\title{
ATRIBUTOS DO SOLO E CRESCIMENTO DO MILHO DECORRENTES DA ADIÇÃO DE LODO ANAERÓBIO DA ESTAÇÃO DE TRATAMENTO DE EFLUENTES DA PARBOILIZAÇÃO DO ARROZ ${ }^{(1)}$
}

\author{
Giúlia D’Avila Vieira ${ }^{(2)}$, Danilo Dufech Castilhos ${ }^{(3)} \&$ Rosa Maria \\ Vargas Castilhos ${ }^{(3)}$
}

\begin{abstract}
RESUMO
O resíduo do processo de parboilização do arroz apresenta alta quantidade de elementos como $\mathrm{N}$ e $\mathrm{P}$, dentre outros, que, uma vez incorporados ao solo, poderão servir como fonte de nutrientes. Nesse sentido, o presente trabalho avaliou alguns atributos de um Argissolo, a produção de massa seca e o estado nutricional do milho cultivado após a adição de lodo anaeróbio originado do processo de parboilização do arroz. O experimento foi instalado em vasos com capacidade para $4,0 \mathrm{~kg}$ de solo e com quatro repetições. Foram estudados os seguintes tratamentos: testemunha; adubação NPK; 2,15, 4,31, 8,62, 12,93, e 17,24 $\mathrm{g} \mathrm{kg}^{-1} \mathrm{de}^{\mathrm{d}}$ lodo (base seca) no solo. A aplicação de lodo aumentou o rendimento de matéria seca do milho, assim como os valores de $\mathrm{pH}$, condutividade elétrica e os teores de $\mathrm{N}, \mathrm{P}, \mathrm{K}$ e Na do solo. As doses de lodo aumentaram também os teores de N, P e K e diminuíram os de Ca e Mg, da parte aérea do milho.
\end{abstract}

Termos de indexação: Zea mays, biossólido, nutrientes, descarte de resíduos.

SUMMARY: SOIL PROPERTIES, DRY MATTER OF MAIZE AFTER APPLICATION OF ANAEROBIC SLUDGE FROM THE SEWAGE TREATMENT STATION OF RICE PARBOILING WASTE WATER

The residue of the process of parboiling rice contains high amounts of elements such as nitrogen, phosphorus and others which, once incorporated into the soil, could serve as a source

\footnotetext{
(1) Parte da Dissertação de Mestrado do primeiro autor. Recebido para publicação em agosto de 2009 e aprovado em janeiro de 2011.

${ }^{(2)}$ Professora Instituto Federal Sul Rio-Grandense - IFSul. Pça. Vinte de Setembro 455, Centro, CEP 96015-360 Pelotas (RS). Email: giulia_vieira@yahoo.com.br

${ }^{(3)}$ Professores Associados do Departamento de Solos, Faculdade de Agronomia "Eliseu Maciel", Universidade Federal de Pelotas - PPGA/UFPel. Caixa Postal 354, CEP 96010-900 Pelotas (RS). E-mail: danilodc@ufpel.tche.br
} 


\begin{abstract}
of nutrients. Accordingly, the present study evaluated some properties of an Ultisol, the dry matter production and nutritional status of corn grown after applying an anaerobic sludge originated from the process of parboiling rice. The experiment was conducted in $4 \mathrm{~kg}$ pots filled with soil, in four replications. The following treatments were studied: control, NPK fertilization, 2.15, 4.31, 8.62, 12.93, and17.24 $\mathrm{g} \mathrm{kg}^{-1}$ sludge. Sludge application from parboiled rice increased the maize dry matter yield, as well as $p H$, electrical conductivity and the concentration of N, P, K and Na in the soil. The sludge also increased the concentration of N, P and $K$ and decreased Ca and $M g$ in the maize shoots.
\end{abstract}

Index terms: Zea mays, biosolids, nutrients, waste disposal.

\section{INTRODUÇÃO}

O arroz parboilizado representa $25 \%$ do total de arroz produzido no Brasil. Para cada quilograma de arroz sujeito a esse processo são gerados quatro litros de um efluente que, após tratado, origina um resíduo na forma de lodo, rico em substâncias orgânicas, $\mathrm{N}$ e $\mathrm{P}$, dentre outros nutrientes, podendo ser empregado como adubo natural, eliminando-se a possibilidade de formação de passivo ambiental dessa atividade (Faria et al., 2006).

Dados a respeito da caracterização e utilização do lodo anaeróbio da estação de tratamento de efluentes da parboilização de arroz na agricultura ainda são escassos na literatura. Muitas pesquisas são direcionadas à utilização do lodo de esgoto e, ou, de curtume, o que permite que se faça uma comparação entre os resíduos, para avaliação dos efeitos de sua aplicação no solo.

A aplicação de lodo de esgoto ao solo tem propiciado elevação dos teores de P (Silva et al., 2002), C orgânico (Cavallaro et al., 1993), pH, condutividade elétrica e capacidade de troca de cátions (Oliveira et al., 2002). Outros trabalhos realizados com lodo de curtume têm demonstrado aumentos no teor de nutrientes no solo e no rendimento de milho (Konrad \& Castilhos, 2002; Ferreira et al., 2003). No entanto, ao contrário do lodo da parboilização do arroz, tanto o lodo de curtume como o de esgoto possuem concentrações de metais pesados que, uma vez no sistema solo-planta, podem contaminar alimentos e, ou, alterar a atividade microbiana do solo, diminuindo, a longo prazo, a disponibilidade de nutrientes a partir de resíduos adicionados.

O P é o nutriente que se encontra em maior quantidade no lodo anaeróbio da parboilização do arroz, seguido do $\mathrm{N}$ e K. Além disso, esse resíduo apresenta $\mathrm{pH}$ alcalino, pelo fato de o processo anaeróbio envolver reações de redução, com consumo de $\mathrm{H}^{+}$, possibilitando efeito auxiliar na neutralização da acidez do solo.

Diante do exposto, o presente trabalho objetivou avaliar alguns atributos de um Argissolo, a produção de massa seca e o estado nutricional do milho cultivado após a adição de lodo anaeróbio originado do processo de parboilização do arroz.

\section{MATERIAL E MÉTODOS}

O experimento foi conduzido utilizando-se, como unidades experimentais, vasos plásticos contendo $4 \mathrm{~kg}$ de solo da camada de 0-20 cm de um Argissolo Vermelho-Amarelo PAD (Embrapa, 1999) coletado na Estação Experimental da Palma, da UFPel. O lodo anaeróbio foi coletado na estação de tratamento de efluentes da parboilização de arroz, na indústria de beneficiamento de arroz Nelson Wendt, localizada na Avenida Leopoldo Bröd, 101 - Bairro Três Vendas, no município de Pelotas/RS. A caracterização do solo e do lodo foi efetuada segundo o método descrito por Tedesco et al. (1995) e está descrita no quadro 1.

Os tratamentos foram: adubação NPK; $0,0 \mathrm{~g} \mathrm{~kg}^{-1}$ no solo (testemunha), 2,15, 4,31, 8,62, 12,93, $17,24 \mathrm{~g} \mathrm{~kg}^{-1}$ de lodo anaeróbio de parboilização no solo.

As doses de NPK foram determinadas de acordo com a análise química do solo, utilizando-se a recomendação da Comissão de Química e Fertilidade do Solo/NRS (CQFS/NRS, 2004) para a cultura do milho. Foram aplicados em $\mathrm{mg} \mathrm{kg}^{-1}$ de solo: $128 \mathrm{de} \mathrm{N}$ (ureia), 180 de $\mathrm{P}$ (superfosfato triplo) e 100 de K (cloreto de K). O lodo obtido para realização deste trabalho apresentou baixo poder de neutralização da acidez (Quadro 1). Devido a isso, e para garantia da elevação do $\mathrm{pH}$ do solo a 6,0, aplicou-se calcário em todos os tratamentos na forma de $\mathrm{CaCO}_{3}+\mathrm{MgCO}_{3}(2: 1)$, na dose de 1,12 $\mathrm{g} \mathrm{kg}^{-1}$ de solo. As quantidades de lodo dos tratamentos foram calculadas após a determinação do teor de $\mathrm{N}$ do resíduo, sendo aplicados 25, 50, 100, 150 e $200 \%$, respectivamente, da quantidade necessária para suprir a exigência de $\mathrm{N}$ da cultura do milho, conforme a Comissão de Química e Fertilidade do Solo/NRS (CQFS/NRS, 2004), o que equivaleu a 4,$3 ; 8,6 ; 17,2 ; 25,9$ e $34,5 \mathrm{Mg} \mathrm{ha}^{-1}$ do lodo. O experimento foi disposto em delineamento completamente casualizado com quatro repetições, num total de 28 unidades.

Após a aplicação e mistura dos tratamentos com o solo, semeou-se milho, cultivar BM 2202-Biomatrix híbrido, que foi desbastado após 10 dias da semeadura, mantendo-se duas plantas por vaso. 
Quadro 1. Atributos do solo, antes do estabelecimento do experimento e do lodo utilizado

\begin{tabular}{|c|c|c|c|}
\hline Solo & Concentração & Lodo & $\begin{array}{l}\text { Concentração } \\
\text { (lodo úmido) }\end{array}$ \\
\hline Argila $\left(\mathrm{g} \mathrm{kg}^{-1}\right)$ & 230 & Umidade $\left(\mathrm{g} \mathrm{kg}^{-1}\right)$ & 952 \\
\hline $\mathrm{pH} \mathrm{H} \mathrm{H}_{2} \mathrm{O}$ & 4,7 & $\mathrm{pH}\left(\mathrm{H}_{2} \mathrm{O}\right)$ & 8,5 \\
\hline pH SMP & 6,2 & Poder de Neutralização (\%) & 7,0 \\
\hline Alumínio $\left(\mathrm{cmol}_{\mathrm{c}} \mathrm{dm}^{-3}\right)$ & 1,8 & Carbono orgânico $\left(\mathrm{g} \mathrm{kg}^{-1}\right)^{(1)}$ & 157,5 \\
\hline Fósforo $\left(\mathrm{mg} \mathrm{dm}^{-3}\right)$ & 3,7 & Fósforo $\left(\mathrm{g} \mathrm{kg}^{-1}\right)^{(1)}$ & 42,4 \\
\hline Potássio $\left(\mathrm{mg} \mathrm{dm}^{-3}\right)$ & 30 & Potássio $\left(\mathrm{g} \mathrm{kg}^{-1}\right)^{(1)}$ & 16,0 \\
\hline Cálcio $\left(\mathrm{cmol}_{\mathrm{c}} \mathrm{dm}^{-3}\right)$ & 0,6 & Cálcio $\left(\mathrm{g} \mathrm{kg}^{-1}\right)^{(1)}$ & 68,4 \\
\hline Magnésio $\left(\mathrm{cmol}_{\mathrm{c}} \mathrm{dm}^{-3}\right)$ & 0,4 & Magnésio $\left(\mathrm{g} \mathrm{kg}^{-1}\right)^{(1)}$ & 84,7 \\
\hline Sódio $\left(\mathrm{mg} \mathrm{dm}^{-3}\right)$ & 11 & Nitrogênio $\left(\mathrm{g} \mathrm{kg}^{-1}\right)^{(1)}$ & 23,51 \\
\hline \multirow{4}{*}{ Carbono orgânico $\left(\mathrm{g} \mathrm{kg}^{-1}\right)$} & 7,0 & Cobre $\left(\mathrm{mg} \mathrm{kg}^{-1}\right)^{(1)}$ & 84 \\
\hline & & Zinco $\left(\mathrm{g} \mathrm{kg}^{-1}\right)^{(1)}$ & 1,7 \\
\hline & & Ferro $\left(\mathrm{g} \mathrm{kg}^{-1}\right)^{(1)}$ & 7,1 \\
\hline & & Manganês $\left(\mathrm{g} \mathrm{kg}^{-1}\right)^{(1)}$ & 31,0 \\
\hline
\end{tabular}

(1) Teores totais.

O experimento foi irrigado diariamente com água destilada, procurando-se manter a umidade equivalente à retenção de 0,03 MPa. Esse procedimento foi efetuado pesando-se diariamente cada vaso e repondo a quantidade de água necessária para manutenção da umidade do solo proposta. A colheita das plantas foi realizada após 41 dias de cultivo.

Ao final do experimento, a parte aérea total das plantas de milho, caule e folhas foi colhida e colocada em estufa a $65^{\circ} \mathrm{C}$, para determinação da matéria seca. Esse material foi moído e submetido à análise dos teores de N, P, K, Ca e Mg, segundo Tedesco et al. (1995).

As amostras de solo foram secas ao ar e peneiradas (2 $\mathrm{mm}$ ) e analisou-se a condutividade elétrica, $\mathrm{pH}, \mathrm{N}$, K, P e Na do solo, segundo método Tedesco et al. (1995).

Os dados obtidos foram submetidos à análise de variância, teste de médias, teste de Duncan a $5 \%$, para comparação do tratamento NPK com as doses do lodo e regressão polinomial, utilizando o programa estatístico Winstat (Machado, 2001).

\section{RESULTADOS E DISCUSSÃO}

\section{Alterações químicas no solo \\ pH}

A aplicação do lodo anaeróbio da estação de tratamento de efluentes da parboilização de arroz causou efeito corretivo adicional sobre o pH do solo em todos os tratamentos, quando comparados aos tratamentos testemunha e adubação NPK. Após 40 dias da implantação do experimento, os tratamentos testemunha e NPK ainda não haviam atingido o $\mathrm{pH}$ recomendado para o milho $(6,0)$, ao contrário dos tratamentos com o lodo, cujos valores foram, em média, 0,8 unidade superiores aos desses tratamentos e aumentaram significativamente com a dose aplicada, apresentando comportamento quadrático (Figura 1).

Apesar de o lodo apresentar baixo poder de neutralização (7\%), fica claro o desempenho desse resíduo quanto ao efeito corretivo do solo, provavelmente devido aos altos teores de carbonato. Conforme Quaggio et al. (1982), os valores de $\mathrm{pH}$ acima de 6,0 podem causar decréscimo no rendimento de matéria seca das plantas, decorrente de um desequilíbrio químico na fertilidade do solo. Com a aplicação conjunta do lodo anaeróbio e calcário, o pH do solo ultrapassou esse valor, atingindo 7,2, sem, no entanto, haver prejuízos ao crescimento das plantas.

\section{Condutividade elétrica (CE) e sódio}

A aplicação do lodo aumentou a condutividade elétrica do solo a valores superiores aos dos tratamentos testemunha e adubação NPK (Figura 2a). A CE variou de 0,08 a $0,22 \mathrm{mS} \mathrm{cm}^{-1}$. Nesse intervalo, o efeito salino é baixo e não ocasiona

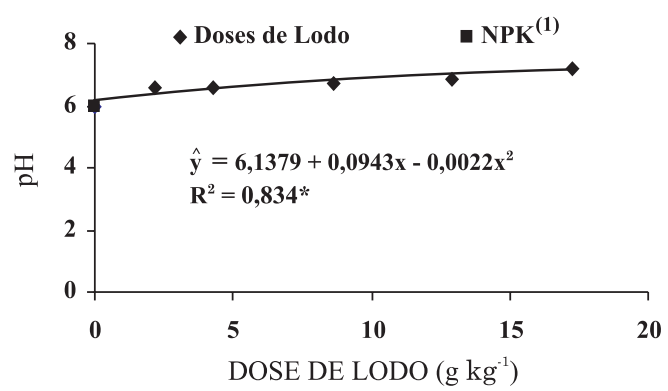

Figura 1. Variação do pH do solo após a aplicação de doses crescentes de lodo anaeróbio da estação de tratamento de efluentes de parboilização de arroz. (1) Tratamento NPK incluído como referência fora da análise de regressão. 

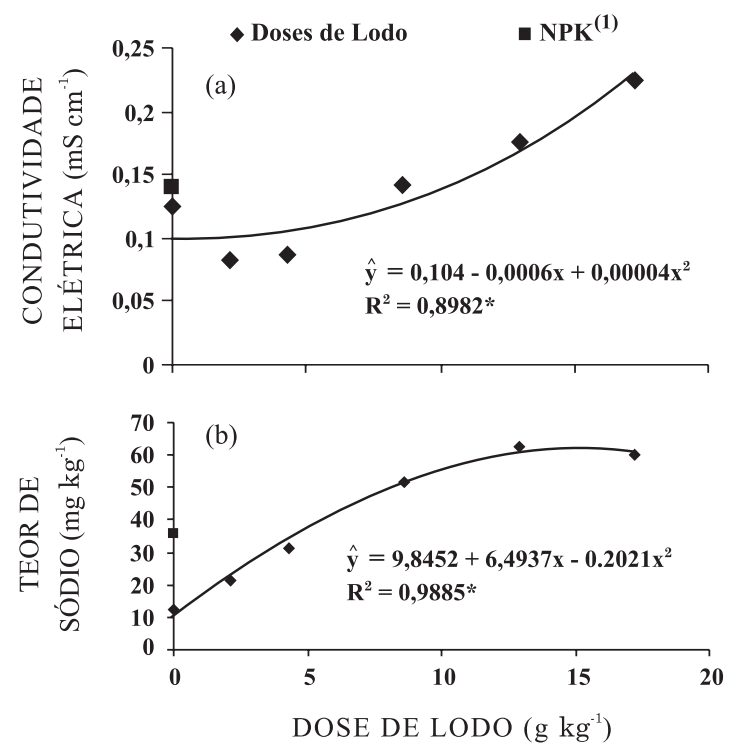

Figura 2. Variação da condutividade elétrica (a) e dos teores de sódio (b) do solo após a aplicação de doses crescentes de lodo anaeróbio da estação de tratamento de efluentes de parboilização de arroz. (1) Tratamento NPK incluído como referência fora da análise de regressão.

problemas de toxidez à cultura. Esses valores ficaram bem abaixo do índice proposto por Pereira (1983), o qual considera como salinos apenas solos cuja condutividade elétrica ultrapasse $4 \mathrm{mS} \mathrm{cm}^{-1}$. Por sua vez, Sangoi et al. (2009) observaram efeitos negativos em plantas de milho quando o cultivo foi realizado em solos com CE superior a $1,0 \mathrm{mS} \mathrm{cm}^{-1}$.

Os teores de $\mathrm{Na}$ no solo também aumentaram significativamente com o incremento das doses de lodo, em relação aos tratamentos testemunha + calcário e adubação NPK (Figura 2b).

O aumento na condutividade elétrica do solo está relacionado à maior disponibilidade de sais, principalmente de $\mathrm{Na}$. A correlação linear simples entre os valores da condutividade elétrica e os teores de $\mathrm{Na}$ observados no solo apresentou $\mathrm{r}=0,68$, significativo a $1 \%$. Esses resultados estão de acordo com os de Aquino Neto \& Camargo (2000), que, analisando a aplicação de doses crescentes de lodo de curtume, observaram que a elevação da condutividade elétrica do solo esteve relacionada também a aumento na disponibilidade desse elemento.

Segundo Lima et al. (1994), a adição de resíduos orgânicos proporciona maior disponibilidade de matéria orgânica ao solo, promovendo aumento na mineralização da matéria orgânica e na capacidade de troca de cátions, contribuindo para o aumento da concentração de íons em solução e, consequentemente, aumento na condutividade elétrica do solo.

\section{Nitrogênio}

A aplicação do lodo provocou efeito linear crescente sobre os teores de $\mathrm{N}$ total do solo (Figura 3a). A partir da primeira dose do resíduo, que incorporou $25 \%$ do $\mathrm{N}$ exigido pelo milho, os teores de $\mathrm{N}$ total do solo já foram significativamente maiores em relação à adubação NPK, que recebeu a ureia como fonte de N. Apesar de as quantidades de $\mathrm{N}$ aplicadas no tratamento NPK e com a dose de 8,62 $\mathrm{g} \mathrm{kg}^{-1}$ do lodo terem sido equivalentes, o $\mathrm{N}$ aplicado na forma de resíduo apresentou teor total $11 \%$ superior ao observado com a aplicação dos nutrientes em sua forma química.

Segundo Alcântara et al. (2007), a mineralização do $\mathrm{N}$ no solo é facilitada quando os resíduos aplicados são de baixa relação $\mathrm{C} / \mathrm{N}$ e, consequentemente, eficientes na disponibilidade de energia, sem excessos, para o bom desempenho da atividade da biomassa microbiana na sua degradação.

\section{Fósforo e potássio}

O teor de $\mathrm{P}$ disponível no solo aumentou significativamente com a aplicação do lodo do arroz (Figura 3b). Esses aumentos são decorrentes do elevado teor de $\mathrm{P}$ do lodo de parboilização do arroz (Quadro 1). Com a aplicação do lodo todos os teores de $\mathrm{P}$ foram superiores estatisticamente ao teor do tratamento com adubação NPK. A eficiência no
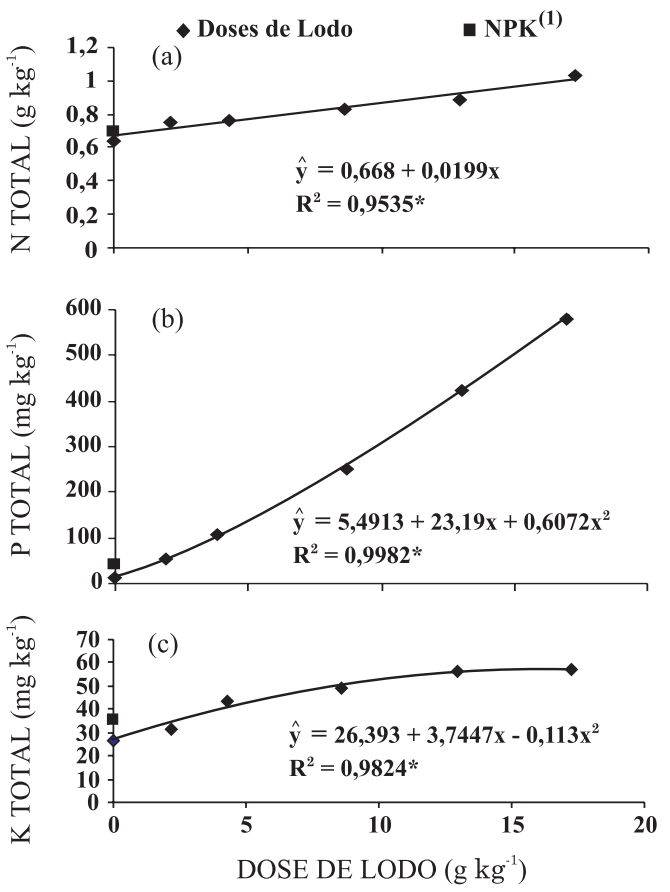

Figura 3. Variação dos teores de nitrogênio (a), fósforo (b) e potássio (c) total no solo após a aplicação do lodo anaeróbio da estação de tratamento de efluentes de parboilização de arroz. (1) Tratamento NPK incluído como referência fora da análise de regressão. 
suprimento de $\mathrm{P}$ com a aplicação do lodo fica evidenciada, uma vez que apenas a primeira dose desse resíduo elevou em $270 \%$ o teor de $\mathrm{P}$ disponível no solo, quando comparado à testemunha. A dose de $\mathrm{P}$ incorporada no solo nos tratamentos que receberam as cinco doses de lodo, correspondem a 1,32; 2,$64 ; 5,28$; 7,91; e 10,56 g/vaso de P. Dessa forma, pode ser verificado que a dose de $2,15 \mathrm{~g} \mathrm{~kg}^{-1}$ (a menor dose de lodo) determinou teor de $\mathrm{P}$ no solo cinco vezes superior à quantidade aplicada desse elemento pelo tratamento NPK, que foi de 0,71 g/vaso.

A alta concentração de P no solo está de acordo com trabalhos de Queiroz \& Koetz (1997), os quais, avaliando teores desse elemento no lodo de parboilização do arroz, verificaram teores de máximos e mínimos de 93,90 e 11,75 $\mathrm{mg} \mathrm{kg}^{-1}$, respectivamente. $\mathrm{O} \mathrm{P}$ encontrado no lodo é proveniente dos resíduos da adubação, de defensivos agrícolas e da hidrólise da fitina, substância presente nas cascas dos grãos que, quando hidrolisada no encharcamento, libera esse nutriente (Faria et al., 2006).

Os teores de $\mathrm{K}$ disponíveis no solo também aumentaram com as doses do lodo, tendo sido significativamente superiores aos do tratamento NPK a partir da dose de 4,31 $\mathrm{g} \mathrm{kg}^{-1}$. Percebe-se que a adição de doses crescentes de lodo proporcionou aumento nas disponibilidades de $\mathrm{P}$ e $\mathrm{K}$ do solo, em comparação aos tratamentos testemunha e NPK (Figura 3). Oliveira (1995) observou a necessidade de suplementação de K em solo tratado com lodo de esgoto, devido à carência desse elemento no resíduo. Neste estudo, o lodo utilizado apresentou teores de $\mathrm{K}$ em torno de $16 \mathrm{~g} \mathrm{~kg}^{-1}$, valores superiores aos encontrados em lodos de esgoto e, ou, de curtume, os quais são em torno de $2 \mathrm{~g} \mathrm{~kg}^{-1}$.

\section{Matéria seca das plantas}

A aplicação do lodo provocou efeitos significativos na produção de matéria seca das plantas de milho, em relação aos tratamentos testemunha + calcário e $\mathrm{NPK}+$ calcário. Com a aplicação de $2,15 \mathrm{~g} \mathrm{~kg}^{-1} \mathrm{de}$ lodo, observou-se produção de $21,43 \mathrm{~g} \mathrm{~kg}^{-1}$ de matéria seca -12 vezes superior à produção encontrada no tratamento testemunha + calcário, que foi de $1,67 \mathrm{~g} \mathrm{~kg}^{-1}$ (Figura 4). A produção obtida com o tratamento NPK $\left(20,46 \mathrm{~g} \mathrm{~kg}^{-1}\right)$ foi estatisticamente inferior à das doses do lodo e cerca de 18 \% inferior à máxima produção de matéria seca.

O efeito das doses do lodo na produção de matéria seca da parte aérea das plantas do milho foi estatisticamente significativo (Figura 4). A aplicação do solo proporcionou produção de matéria seca comparável à obtida com a fertilização mineral recomendada, observando-se com a dose de $2,15 \mathrm{~g} \mathrm{~kg}^{-1}$ lodo uma produção de matéria seca também superior à da adubação mineral (Figura 4). Pelos rendimentos obtidos, constatou-se que todos os tratamentos que continham o lodo garantiram a nutrição mínima para o crescimento normal das plantas. Observou-se também que, a partir da dose de 4,31 $\mathrm{g} \mathrm{kg}^{-1}$ lodo, os incrementos sobre

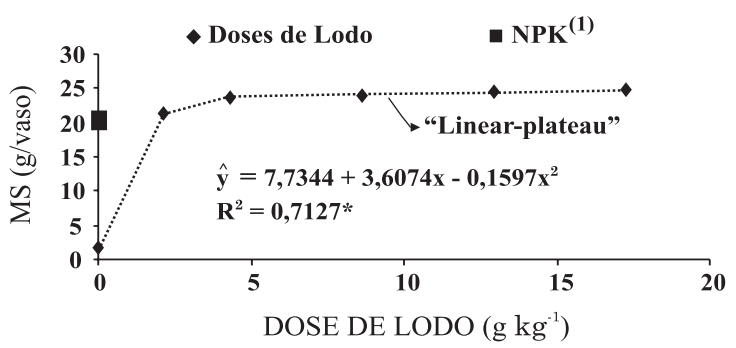

Figura 4. Variação da produção de matéria seca (MS) das plantas de milho em função das doses de lodo anaeróbio da estação de tratamento de efluentes de parboilização de arroz. (1) Tratamento NPK incluído como referência fora da análise de regressão.

a produtividade de matéria seca foram menores, com baixa resposta do crescimento das plantas à presença do resíduo.

\section{Absorção de macronutrientes pelas plantas}

Os teores de $\mathrm{N}$ nas plantas de milho somente foram alterados com a maior dose do lodo $\left(17,24 \mathrm{~g} \mathrm{~kg}^{-1}\right)$, cujos valores foram superiores aos dos demais tratamentos (Figura 5a). Observou-se, no decorrer do experimento, que o lodo não foi eficiente no suprimento de $\mathrm{N}$ para as plantas. Segundo a Comissão de Química e Fertilidade do Solo/NRS (CQFS/NRS, 2004), o intervalo de suficiência para o $\mathrm{N}$ na matéria seca do milho, aos 30-45 dias após a emergência, é de 27 a $35 \mathrm{~g} \mathrm{~kg}^{-1}$, o que justifica a clorose observada nas pontas e margens das folhas mais velhas, após 20 dias de aplicação do resíduo, evidenciando que os teores encontrados desse nutriente ficaram abaixo dos teores exigidos para essa cultura em todos os tratamentos.

Os teores de $\mathrm{N}$ no solo, para se tornarem disponíveis às plantas, dependem da taxa de mineralização da matéria orgânica. Considerando que o $\mathrm{N}$ apresenta uma dinâmica de transformações, pode ocorrer uma série de reações, que levam, sobretudo, à baixa eficiência de utilização do $\mathrm{N}$ aplicado na forma de resíduo. Isso pode ser atribuído principalmente à desnitrificação e à volatilização de amônia, além da provável imobilização desse nutriente pela microbiota do solo (Coelho et al., 1991), o que pode justificar a baixa absorção de $\mathrm{N}$ pelo milho neste trabalho.

$\mathrm{O}$ teor de $\mathrm{P}$ na parte aérea do milho apresentou aumento significativo com a aplicação do resíduo. Verificou-se que as aplicações do lodo superiores a 4,31 $\mathrm{g} \mathrm{kg}^{-1}$ determinaram valores de $\mathrm{P}$ superiores aos observados com a testemunha $\left(0,0 \mathrm{~g} \mathrm{~kg}^{-1}\right.$ de lodo) e, ou, tratamento NPK (Figura 5b).

$\mathrm{O}$ aporte de $\mathrm{P}$ ao solo decorrente da alta concentração desse elemento no lodo justificou o aumento nos teores de $\mathrm{P}$ nas folhas de milho. Nos tratamentos com o lodo e também no tratamento NPK, detectaram-se valores de P na parte aérea acima da faixa de suficiência desse elemento exigida pela 

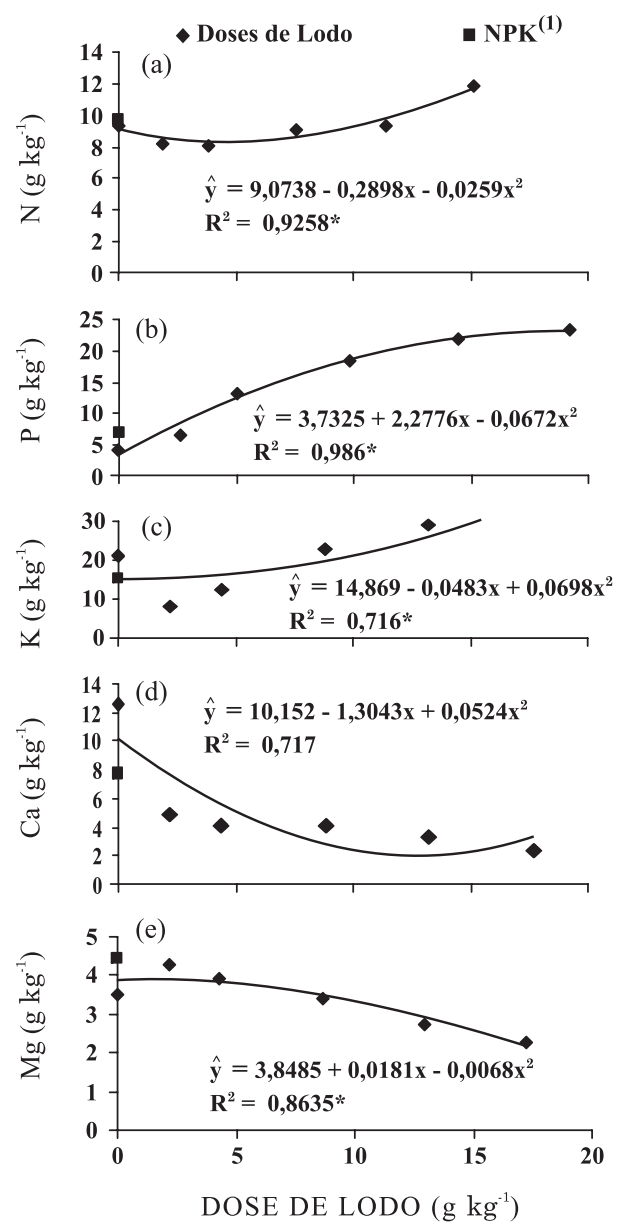

Figura 5. Variação dos teores de nitrogênio (a), fósforo (b), potássio (c), cálcio (d) e magnésio (e) nas folhas de milho após a aplicação ao solo do lodo anaeróbio da estação de tratamento de efluentes de parboilização de arroz ao solo. (1) Tratamento NPK incluído como referência fora da análise de regressão.

cultura do milho, que é de 2 a $4 \mathrm{~g} \mathrm{~kg}^{-1}$ de matéria seca - Comissão de Química e Fertilidade do Solo/ NRS (CQFS/NRS, 2004).

Os teores de K nas folhas de milho apresentaram crescimento significativo com a aplicação do lodo (Figura 5c). A partir da terceira dose aplicada de lodo, os teores foram superiores aos do tratamento testemunha e da adubação NPK. Os teores de Ca na parte aérea do milho, em todos os tratamentos com o lodo foram inferiores estatisticamente aos dos tratamentos testemunha e adubação NPK (Figura 5d). O maior teor de Ca com a dose zero de lodo pode ser explicada pelo efeito de concentração desse elemento em tratamentos em que a produção de matéria seca é menor. Com o maior suprimento de NPK, observou-se, nos tratamentos com o lodo, um efeito contrário, com menor teor de Ca em função do efeito de diluição desse elemento, ocasionado pelo maior crescimento das plantas.
O maior teor de $\mathrm{Mg}$ na parte aérea do milho foi detectado com o tratamento adubação NPK (Figura 5e). Apenas as duas primeiras doses de lodo promoveram teores superiores aos do tratamento testemunha. À semelhança do Ca, a aplicação do lodo provocou diminuição na absorção de $\mathrm{Mg}$ (Figura 5e).

A bibliografia sobre efeitos da aplicação do lodo de parboilização do arroz no solo é praticamente inexistente. Aumentos na produção de matéria seca de plantas de milho em solos tratados com doses de lodo de esgoto e de curtume já foram observados por Da Ros et al. (1993), Berton et al. (1997) e Konrad \& Castilhos (2002). Em que pese a possibilidade de contaminação do solo com o uso agrícola desses resíduos, a utilização do lodo de parboilização do arroz apresenta vantagens devido à ausência de metais pesados e prováveis contaminantes. Pelos valores observados neste estudo, e respeitadas as doses aplicadas, verifica-se que o lodo causou menor aumento na condutividade elétrica do solo, quando comparado a outros resíduos, como o lodo de esgoto (Bettiol \& Fernandes, 2004) e lodo de curtume (Costa et al., 2001), aplicados ao solo. Castilhos et al. (2002) verificaram aumento de $14 \%$ no teor de $\mathrm{N}$ total do solo com doses de resíduo de curtume que incorporavam $518,0 \mathrm{~kg} \mathrm{ha}^{-1}$ $\mathrm{N}$-quantidade muito superior ao $\mathrm{N}$ incorporado nesse estudo com o lodo de parboilização do arroz. Quin \& Woods (1978) também observaram aumento no teor de $\mathrm{N}$ total em diferentes tipos de solo submetidos a doses crescentes de lodo de esgoto. Contudo, esses valores indicam o $\mathrm{N}$ total, e não o disponível, pois a disponibilidade do $\mathrm{N}$ orgânico depende da eficiência de mineralização e da taxa de decomposição do resíduo no solo.

Linden et al. (1983) observaram que a aplicação de lodos como o de esgoto ao solo implica suplementação extra de $\mathrm{K}$ devido à baixa concentração de $\mathrm{K}$, em torno de $2 \mathrm{~g} \mathrm{~kg}^{-1}$, nesse resíduo. Entretanto, o lodo utilizado no presente estudo apresentou teores de $\mathrm{K}$ em torno de $16 \mathrm{~g} \mathrm{~kg}^{-1}$ de resíduo, promovendo aumento na disponibilidade de K, como pode ser observado a partir da aplicação de $8,62 \mathrm{~g} \mathrm{~kg}^{-1}$ de lodo, cujos teores encontram-se dentro do intervalo de suficiência desse elemento exigido pelo milho: entre 17 e $35 \mathrm{~g} \mathrm{~kg}^{-1}$.

Barbosa et al. (2002), em experimento com milho cultivado em solo tratado com lodo de esgoto, constataram aumento nos teores de Ca e Mg trocáveis. No entanto, no presente experimento, verificou-se que, com o aumento das doses de lodo, ocorreu diminuição nos teores absorvidos desses dois nutrientes. A partir disso, deve-se considerar que o lodo utilizado nos tratamentos, além de conter altas concentrações de $\mathrm{Ca}$ e $\mathrm{Mg}$, possui considerável concentração de $\mathrm{K}$, o que pode inibir, competitivamente, a absorção de $\mathrm{Ca}$ e, principalmente, a de $\mathrm{Mg}$ pelas raízes das plantas. Segundo Malavolta et al. (1997), a absorção de cátions pelas plantas não é um processo específico e depende sobretudo da concentração de íons catiônicos no meio nutritivo e, em muitos casos, da permeabilidade 
específica das membranas a um determinado cátion. Dessa forma, pode ocorrer competição não específica entre os cátions pelas cargas negativas da célula. $\mathrm{O}$ $\mathrm{K}$, que é absorvido rapidamente pela célula, seja por processo ativo ou por difusão facilitada, compete fortemente na absorção de cátions, principalmente o $\mathrm{Ca}$ e o $\mathrm{Mg}$.

\section{CONCLUSÕES}

1. A aplicação no solo do lodo anaeróbio da estação de tratamento de efluentes de parboilização de arroz aumentou o rendimento da matéria seca do milho; $25 \%$ da dose recomendada para o suprimento de $\mathrm{N}$ na cultura já foi suficiente para proporcionar rendimento superior ao do tratamento NPK.

2. A aplicação do lodo ao solo aumentou o pH, a condutividade elétrica e os teores de N, P, K e Na do solo.

3. A aplicação no solo do lodo aumentou os teores de $\mathrm{N}, \mathrm{P}$ e K e diminuiu os de $\mathrm{Ca}$ e $\mathrm{Mg}$, da parte aérea do milho.

\section{LITERATURA CITADA}

ALCÃNTARA, M.A.K.; AQUINO NETO, V. \& CAMARGO, O.A. Mineralização do nitrogênio em solos tratados com lodos de curtume. Pesq. Agropec. Bras., 42:548-555, 2007.

AQUINO NETO, V. \& CAMARGO, O.A. Crescimento e acúmulo de cromo em alface cultivada em dois Latossolos tratados com $\mathrm{CrCl}_{3}$ e resíduos de curtume. R. Bras. Ci. Solo, 24:225-235, 2000.

BARBOSA, G.M.C.; TAVARES FILHO, J. \& FONSECA, I.C.B. Propriedades químicas de um Latossolo Vermelho eutroférrico após aplicação por dois anos consecutivos de lodo de esgoto. Acta Sci., 24:1501-1505, 2002.

BERTON, R.S.; VALADARES, J.M.A.S.; CAMARGO, O.A. \& BATAGLIA, O.C. Peletização do lodo de esgoto e adição de $\mathrm{CaCO}_{3}$ na produção de matéria seca e absorção de $\mathrm{Zn}$, $\mathrm{Cu}$ e Ni pelo milho em três Latossolos. R. Bras. Ci. Solo, 21:685-691, 1997.

BETTIOL, W. \& FERNANDES, S.A.P. Efeito do lodo de esgoto na comunidade microbiana e atributos químicos do solo. Jaguariúna, Embrapa Meio Ambiente, 2004. 5p. (Comunicado Técnico, 24)

COELHO, A.M.; FRANÇA, G.E. \& BAHIA FILHO, A.F.C. Nutrição e adubação do milho forrageiro. In: EMPRESA BRASILEIRA DE PESQUISA AGROPECUÁRIA EMBRAPA. Centro Nacional de Pesquisa de Milho e Sorgo. Milho para silagem: Tecnologias, sistemas e custo de produção. Sete Lagoas, 1991. p.29-73. (EmbrapaCNPMS. Circular Técnica, 14)
CASTILHOS, D.D.; TEDESCO, M.J. \& VIDOR, C. Rendimento de culturas e alterações químicas do solo tratado com resíduos de curtume e cromo hexavalente. R. Bras. Ci. Solo, 26:1083-1092, 2002.

CAVALLARO, N.; PADILLA, N. \& VILLARRUBIA, J. Sewage sludge effects on chemical properties of acid soils. Soil Sci., 156:63-70, 1993.

COMISSÃO DE QUÍMICA E FERTILIDADE DO SOLO CQFS. Manual de adubação e de calagem para os Estados do RS e SC. 10.ed. Porto Alegre, Sociedade Brasileira de Ciência do solo - Núcleo Regional Sul, 2004. 394p.

COSTA, C.N.; CASTILHOS, D.D.; CASTILHOS, R.M.V.; KONRAD, E.; PASSIANOTO, C.C. \& RODRIGUES, C.G. Efeito da adição de lodos de curtume sobre as alterações químicas do solo, rendimento de matéria seca e absorção de nutrientes em soja. R. Bras. Agroci., 7:189-191, 2001.

DA ROS, C.O.; AITA, C.; CERETTA, C.A. \& FRIES, M.R. Lodo de esgoto: Efeito imediato no milheto e residual na associação aveia-ervilhaca. R. Bras. Ci. Solo, 17:257-261, 1993.

EMPRESA BRASILEIRA DE PERSQUISA AGROPECUÁRIA - EMBRAPA. Centro Nacional de pesquisa em solos. Sistema brasileiro de classificação de solos. Brasília, Produção de informação; Rio de Janeiro, Embrapa Solos, 1999. 412p.

FARIA, O.L.; KOETZ, P.R.; SANTOS, M.S. \& NUNES, W.A. Remoção de fósforo de efluentes da parboilização de arroz por absorção biológica estimulada em reator em batelada seqüencial (RBS). Ci. Técnol. Alim., 26:309-317, 2006.

FERREIRA, A.S.; CAMARGO, F.A.O.; TEDESCO, M.J. \& BISSANI, C.A. Alterações de atributos químicos e biológicos de solo e rendimento de milho e soja pela utilização de resíduos de curtume e carbonífero. R. Bras. Ci. Solo, 27:755-763, 2003.

KONRAD, E.E. \& CASTILHOS, D.D. Alterações químicas do solo e crescimento do milho decorrente da adição do lodo de curtume. R. Bras. Ci. Solo, 26:257-265, 2002.

LIMA, V.C.; LIMA, J.M.J.C.; EDUARDO, B.J.F.P. \& CERRI, C.C. Conteúdo de carbono e biomassa microbiana em agroecossistemas: Comparação entre métodos de preparo do solo. R. Setor Ci. Agr., 1391:297-302,1994.

LINDEN, D.R.; CLAPP, C.E. \& DOWDOY, R.H. Hydrologic management: Nutrients. In: PAGE, A.L.; GEASON, T.L.; SMITH, I.E.; ISKANDAR, J.K. \& SUMMERS, L.E., eds. Utilization of municipal wastewater and sludge on land. Riverside, University of California, 1983. p.79-103.

MACHADO, A. Sistema de análise estatística para Windows (Winstat). Pelotas, Universidade Federal de Pelotas, 2001.

MALAVOLTA, E.; VITTI, G.C. \& SILVA, S.A. Avaliação do estado nutricional das plantas: Princípios e aplicações. 2.ed. Piracicaba, Potafos, 1997. 319p.

OLIVEIRA, F.C. Metais pesados e formas nitrogenadas em solos tratados com lodo de esgoto. Piracicaba, Universidade de São Paulo, 1995. 90p. (Tese de Mestrado) 
OLIVEIRA, F.C.; MATIAZZO, M.E.; MARCIANO, C.R. \& ROSSETO, R. Efeitos de aplicações sucessivas de lodo de esgoto em Latossolo Amarelo distrófico cultivado com cana-de-açucar: Carbono orgânico, condutividade elétrica, pH e CTC. R. Bras. Ci. Solo, 26:505-519, 2002.

PEREIRA, J.R. Solos salinos e sódicos. In: RAIJ, B.van; BATAGLIA, O.C. \& SILVA, N.M., eds. Acidez e calagem no Brasil. Campinas, Sociedade Brasileira de Ciência do solo, 1983. p.127-143.

QUAGGIO, J.A.; MASCARENHAS, H.A.A. \& BATAGLIA, O.C. Resposta da soja à aplicação de doses crescentes de calcário em Latossolo Roxo distrófico do Cerrado. R. Bras. Ci. Solo, 6:113-118, 1982.

QUEIROZ, M.I. \& KOETZ, P.R. Caracterização do efluente da parboilização do arroz. R. Bras. Agroci., 3:139-143, 1997.
QUIN, B.F. \& WOODS, P.H. Surface irrigation of pasture with treated sewage effluent. Nutrient status of soil and pastures. New Zealand J. Agric. Res., 21:419-426, 1978.

SANGOI, L.; ERNANI, P.R.; BIANCHET, P.; VARGAS, V.P. \& PICOLI. G.J. Efeito de doses de cloreto de potássio sobre a germinação e o crescimento inicial do milho, em solos com texturas contrastantes. R. Bras. Milho Sorgo, 8:187-197, 2009.

SILVA, J.E.; RESCK, D.V.S. \& SHARMA, R.D. Alternativa agronômica para o biossólido produzido no Distrito Federal - Efeito na produção de milho e adição de metais pesados em Latossolo no cerrado. R. Bras. Ci. Solo, 26:487-495, 2002.

TEDESCO, M.J.; GIANELLO, C. \& BISSANI, C.A. Análise de solos, plantas e outros materiais. Porto Alegre, Universidade Federal do Rio Grande do Sul, 1995. 174p. 